\title{
Metal-Supported Niobium Catalysts Investigation for Conversion of Bio-Renewable Glycerol to Organic Compounds
}

\author{
Carolina F. M. Pestana, ${ }^{a}$ Bianca P. Pinto, ${ }^{\circledR a}$ Daniella R. Fernandes ${ }^{a}$ and \\ Claudio J. A. Mota ${ }^{\circledR *, a, b, c}$ \\ ${ }^{a}$ Instituto de Química, Universidade Federal do Rio de Janeiro, Av. Athos da Silveira Ramos 149, \\ CT Bl A, 21941-909 Rio de Janeiro-RJ, Brazil \\ ${ }^{b}$ Escola de Química, Universidade Federal do Rio de Janeiro, Av. Athos da Silveira Ramos 149, \\ CT Bl E, 21941-909 Rio de Janeiro-RJ, Brazil \\ 'INCT Energia \& Ambiente, Universidade Federal do Rio de Janeiro, \\ 21941-909 Rio de Janeiro-RJ, Brazil
}

\begin{abstract}
The glycerol oxidative dehydration to organic compounds, especially acrolein and acrylic acid, was studied over vanadium, molybdenum, and cobalt oxides supported on niobium oxide and niobium phosphate catalysts. At $300{ }^{\circ} \mathrm{C}$, the glycerol conversion was $100 \%$ over all catalysts tested, and acrolein was the main product observed, without significant deactivation within the time on stream studied. Except for $\mathrm{Co} / \mathrm{V} / \mathrm{Nb}_{2} \mathrm{O}_{5}$, acrylic acid was formed over all catalysts, but the selectivity was not higher than $10 \%$. Acetaldehyde and acetic acid were the other organic oxygenated products formed. Although the catalysts supported over $\mathrm{Nb}_{2} \mathrm{O}_{5}$ presented significantly lower acidity than the catalysts supported over $\mathrm{NbOPO}_{4}$, they showed $100 \%$ glycerol conversion, indicating that the dehydration of glycerol does not require strong acidity. These data indicate the potential of niobium-based supports in the development of an active and selective catalyst for the glycerol oxidehydration to acrolein and acrylic acid, chemicals of great importance in the industry.
\end{abstract}

Keywords: acrolein, acrylic acid, dehydration, glycerol, niobium-base catalysts, oxidation

\section{Introduction}

Presently, a major part of the glycerol produced in the world comes from the transesterification of oils and fats for the production of biodiesel. In this process, approximately $100 \mathrm{~kg}$ of glycerol as a byproduct is inevitably generated when a ton of biodiesel is produced, causing a significant surplus of this product in recent years, due to the increase in the production of biofuel. ${ }^{1}$ As a result, many efforts have been made to find new uses for the glycerol produced as a byproduct, especially as a renewable raw material for the chemical industry. ${ }^{2-4}$ Acid-catalyzed dehydration of glycerol is an excellent opportunity to produce high value-added chemicals, such as hydroxyacetone (acetol), acrolein, and acrylic acid. The major use of acrolein is in the production of acrylic acid, ${ }^{5,6}$ and acetol is mainly used as an intermediate for the production of other chemicals, such as

*e-mail: cmota@iq.ufrj.br

Editor handled this article: Jaísa Fernandes Soares propylene glycol. It is also used to synthesize compounds such as propionaldehyde, acetone, and furan derivatives. ${ }^{7}$

The conversion of glycerol to acrylic acid may be carried out either in two steps, firstly involving the acid-catalyzed dehydration to acrolein and its subsequent oxidation to acrylic acid by the conventional V/Mo catalysts, or in a single step, involving the oxidehydration of glycerol over a bifunctional catalyst (containing acid and metallic functions) in the presence of air or oxygen (Scheme 1). This process has been receiving particular attention, because of the reduction of operational and capital expenditures compared with the two-step process. ${ }^{89}$ Nevertheless, the development of catalytic systems and reaction conditions for the one-step process is challenging, because dehydration is endothermic and favored at high temperatures, whereas oxidation of the formed acrolein is exothermic and difficult to be controlled at high temperatures, ultimately ending in $\mathrm{CO}_{2}$.

Some studies on one-step glycerol oxidehydration have been reported. Wang et al. ${ }^{9}$ designed a catalyst featuring 


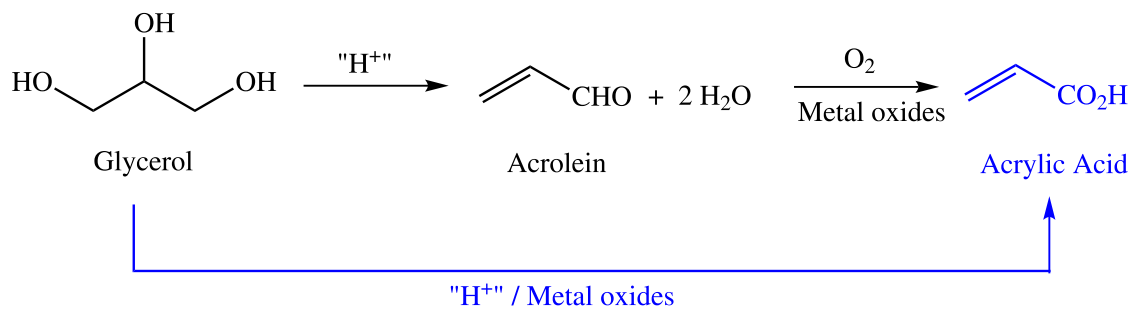

Scheme 1. Glycerol routes to acrylic acid.

$\mathrm{FeO}_{\mathrm{x}}$ domains embedded on the surface of $\mathrm{FeVO}_{4}$ phase, to evaluate its performance in the oxidative dehydration of glycerol. The best acrylic acid yield was $14 \%$ over the $\mathrm{Fe}_{1.2} \mathrm{~V}$ catalyst. Soriano et al..$^{10}$ reported the use of tungsten and vanadium mixed oxides for the same reaction. It was reported an ideal $\mathrm{V} /(\mathrm{W}+\mathrm{V})$ ratio $(0.12$ to 0.21$)$ for combining both the acid properties of tungsten oxide, which is an efficient catalyst for glycerol dehydration into acrolein in presence of oxygen, and the oxidizing properties of the vanadium ions. Chieregato et al. ${ }^{11}$ also reported the use of tungsten and vanadium mixed oxides as catalysts for glycerol oxidehydration and found selectivity to acrylic acid of $25 \%$. However, when niobium was incorporated in the structure, the acrylic acid selectivity was increased to $34 \%$, showing a positive effect on the selectivity to acrolein and acrylic acid.

The glycerol oxidehydration to acrylic acid over vanadium impregnated zeolite was previously studied. The results were interpreted in terms of the vanadium dispersion inside the zeolite pores. For higher vanadium contents, the metal concentration on the outer zeolite surface increases, favoring the direct glycerol oxidation and preventing dehydration with the ultimate formation of acrylic acid. ${ }^{12}$ Possato et al. ${ }^{13}$ reported an oxide-impregnated bifunctional zeolite catalyst for the glycerol oxidehydration, observing $97 \%$ of glycerol conversion and selectivity towards acrylic acid close to $17 \%$, under air atmosphere. Other organic products were also observed, including acrolein and acetaldehyde. Although acrylic acid was produced on pure $\mathrm{V}_{2} \mathrm{O}_{5}$, the glycerol conversion was low (5\%), even at high temperatures $\left(350^{\circ} \mathrm{C}\right)$. In addition, high selectivity to acetic acid was observed.

Paula et al..$^{14}$ synthesized vanadium silicates, isostructural to the titanium silicates ETS-10 and AM-6, which are active and selective for the glycerol oxidehydration to acrylic acid. ${ }^{14}$ The best performance was $94 \%$ of glycerol conversion and $86 \%$ selectivity to acrylic acid at $350{ }^{\circ} \mathrm{C}$ for $1 \mathrm{~h}$ of time stream in $100 \% \mathrm{O}_{2}$ atmosphere. However, when the reaction was carried out in $20 \%$ of $\mathrm{O}_{2}$, the glycerol conversion and acrylic acid selectivity decreased to 63 and $19 \%$, respectively. Omata et al..$^{15}$ studied a complex oxide of tungsten, vanadium, and niobium as a catalyst for the direct oxidative transformation of glycerol to acrylic acid. It was observed $100 \%$ of glycerol conversion and $37 \%$ of acrylic acid selectivity. The acrylic acid selectivity was improved to 59\% upon modification of the catalyst surface with $2.5 \mathrm{wt}$.\% of phosphoric acid.

The gas phase glycerol conversion to acrylic acid over heteropoly acids was reported by $\mathrm{Li}$ and Zhang. ${ }^{16}$ The $\mathrm{Cs}(\mathrm{VO})_{0.2}(\mathrm{PMo})_{0.25}(\mathrm{PW})_{0.75}$ catalyst showed the best result, with $100 \%$ glycerol conversion and acrylic acid yield up to $60 \%$, at $340{ }^{\circ} \mathrm{C}$ for $1 \mathrm{~h}$ of reaction. After $56 \mathrm{~h}$ of time on stream, the acrylic acid yield decreased to about $38 \%$, showing good stability for coke deposition.

Martins and co-workers ${ }^{17}$ have studied the glycerol oxidehydration to acrylic acid. ${ }^{17-19}$ The authors evaluated the hydrothermal synthesis effects and heat-treatment in the formation of the crystalline phase of the vanadium and molybdenum mixed oxides. The catalysts treated under $100 \%$ oxidizing atmosphere showed the best catalytic performance to acrylic acid, achieving $33 \%$ selectivity at $320^{\circ} \mathrm{C}$. A gas flow rich in $\mathrm{O}_{2}$ resulted in a suitable equilibrium in the phase formation of the mixed oxides containing $\mathrm{V}^{4+}$ and $\mathrm{V}^{5+}\left(\mathrm{MoVO}_{5}\right.$ and $\mathrm{Mo}_{4.65} \mathrm{~V}_{0.35} \mathrm{O}_{14}$, respectively). Later, it was explored the influence of surfactants on the synthesis of molybdenum and vanadium mixed oxides for the glycerol oxidehydration..$^{18}$ Both catalysts presented higher acrylic acid selectivity and good catalytic stability, with no coke formation and a considerable decrease in $\mathrm{CO}_{x}$ evolution during $6 \mathrm{~h}$ of reaction. Recently, Al-free vanadium silicates presenting structures analog to ferrierite and ITQ-6 zeolites were evaluated. ${ }^{19}[\mathrm{~V}]-\mathrm{ITQ}-6(40)$ and $[\mathrm{V}]-\mathrm{FER}(25)$ catalysts exhibit acrylic acid selectivity of 34 and $46 \%$, respectively, presenting no significant deactivation after $6 \mathrm{~h}$ on stream. The authors reported that hydroxylated vanadium sites, formed by the dissociative adsorption of water, were responsible for extrinsic acidity and, consequently, glycerol dehydration.

In the present work, we wish to present results of glycerol oxidehydration over vanadium, molybdenum, and cobalt impregnated on niobium supports. To the best of our knowledge, there is no report of the use of these catalysts in this reaction. Compared to zeolites, niobium oxide and niobium phosphate are significantly less acidic, ${ }^{20}$ which may impair the formation of excessive secondary products, 
as well as catalyst deactivation. Besides, the use of niobium as catalyst support will contribute to the Brazilian economy since Brazil has a hegemony position about niobium, being the largest producer of this metal.

\section{Experimental}

\section{Preparation of the catalysts}

The supports of niobium oxide $\left(\mathrm{Nb}_{2} \mathrm{O}_{5}\right)$ and niobium phosphate $\left(\mathrm{NbOPO}_{4}\right)$ were obtained from CBMM (Companhia Brasileira de Metalurgia e Mineração, Araxá, Brazil). Before the metal impregnation, the niobium oxide was calcined at $550{ }^{\circ} \mathrm{C}$ for $2 \mathrm{~h}$ under atmospheric air.

The catalysts were prepared by wet impregnation of the supports using ammonium metavanadate $\left(\mathrm{NH}_{4} \mathrm{VO}_{3}\right)$, ammonium heptamolybdate tetrahydrate $\left(\left(\mathrm{NH}_{4}\right)_{6} \mathrm{Mo}_{7} \mathrm{O}_{24} \cdot 4 \mathrm{H}_{2} \mathrm{O}\right)$ or cobalt nitrate hexahydrate $\left(\mathrm{Co}\left(\mathrm{NO}_{3}\right)_{2} \cdot 6 \mathrm{H}_{2} \mathrm{O}\right)$, all from Sigma-Aldrich, São Paulo, Brazil, analytical grade. Firstly, a given amount of the metallic salts $\left(0.6 \mathrm{~g}\right.$ of $\mathrm{NH}_{4} \mathrm{VO}_{3}, 0.5 \mathrm{~g}$ of $\left(\mathrm{NH}_{4}\right)_{6} \mathrm{Mo}_{7} \mathrm{O}_{24} \cdot 4 \mathrm{H}_{2} \mathrm{O}$ and $0.5 \mathrm{~g}$ of $\mathrm{Co}\left(\mathrm{NO}_{3}\right)_{2} \cdot 6 \mathrm{H}_{2} \mathrm{O}$ for $\mathrm{Mo} / \mathrm{V}$ and $\mathrm{Co} / \mathrm{Mo}$ niobium supported catalysts; $1.2 \mathrm{~g}$ of $\mathrm{Co}\left(\mathrm{NO}_{3}\right)_{2} \cdot 6 \mathrm{H}_{2} \mathrm{O}$ and $0.6 \mathrm{~g}$ of $\mathrm{NH}_{4} \mathrm{VO}_{3}$ for $\mathrm{Co} / \mathrm{V}$ niobium supported catalyst) were dissolved in $70 \mathrm{~mL}$ of distilled water. Then, the support of niobium oxide or niobium phosphate $(5 \mathrm{~g})$ was added, and the system was kept under magnetic stirring at room temperature for $24 \mathrm{~h}$. After this period, the water was carefully evaporated in a rotary evaporator to obtain the impregnated catalysts. After metal impregnation, the catalysts prepared by impregnation on niobium phosphate were calcinated in an oven at $550^{\circ} \mathrm{C}$ for $2 \mathrm{~h}$, whereas the catalysts prepared through the impregnation on niobium oxide were calcinated at $400{ }^{\circ} \mathrm{C}$ for $2 \mathrm{~h}$. The final catalysts were named with the symbol of the impregnated metals and the molecular formula of the support. For instance, $\mathrm{Co} / \mathrm{V} / \mathrm{NbOPO}_{4}$ stands for the catalysts impregnated with cobalt and vanadium oxide over niobium phosphate as support.

\section{Characterization of materials}

The chemical composition of the catalysts was analyzed by X-ray fluorescence (XRF) on a Philips PW 2400 spectrometer (Amsterdam, Netherlands) using a $3 \mathrm{KW}$ Rh tube. The textural properties were analyzed by nitrogen adsorption at $-196{ }^{\circ} \mathrm{C}$ on Micromeritics ASAP 2020 equipment (Norcross, United States). The surface area was determined using the Brunauer-Emmett-Teller (BET) method.

Powder X-ray diffraction (XRD) was obtained on a Shimadzu XRD 6000 X-ray diffractometer (Kyoto, Japan) using $\mathrm{Cu} \mathrm{K} \alpha$ radiation operated at $40 \mathrm{kV}$ and $30 \mathrm{~mA}$. The $\mathrm{X}$-ray patterns were collected in the $2 \theta$ range of $5-80^{\circ}$ (scan speed of $\left.4{ }^{\circ} \mathrm{C} \min ^{-1}\right)$.

The total acidity and acid strength distribution of the supports and impregnated catalysts were estimated by temperature-programmed desorption of $n$-butylamine, following a procedure reported elsewhere. ${ }^{21}$

\section{Catalysts tests}

The catalytic tests were carried out in a continuous flow glass unit coupled online with a gas chromatograph to analyze the reaction products. A U-shaped glass reactor with a lateral stem was loaded with approximately $100 \mathrm{mg}$ of catalyst to form a fixed bed. The catalyst was pretreated under flowing nitrogen $\left(40 \mathrm{~mL} \mathrm{~min}{ }^{-1}\right)$ at $350{ }^{\circ} \mathrm{C}$ for $30 \mathrm{~min}$. The reactor was then cooled to $300{ }^{\circ} \mathrm{C}$ and a $50 \mathrm{vol} \%$ glycerol aqueous solution was introduced at $0.5 \mathrm{~mL} \mathrm{~h}^{-1}$ flow rate through the lateral stem with the aid of a syringe pump. In the oxidative dehydration studies, synthetic air $\left(40 \mathrm{~mL} \mathrm{~min}^{-1}\right)$ was used as carrier gas instead of nitrogen.

The reactor effluent was analyzed by gas chromatography with flame ionization detector (Trace GC Ultra, Thermo Electron Corporation, Santa Clara, United States), using a column DB-225 (30 m, $0.25 \mathrm{~mm}$, and $0.25 \mu \mathrm{m})$ of (50\%-cyanopropylphenyl)-dimethylpolysiloxane as stationary phase, to monitor the glycerol conversion and selectivity to the organic products. In control experiments, a sample of the gas phase was taken and analyzed on a gas chromatograph with a thermal conductivity detector, using Plot Q, a bonded polystyrene-divinylbenzene column ( $30 \mathrm{~m}, 0.320 \mathrm{~nm}$, and $0.20 \mu \mathrm{m}$ ).

The conversion of glycerol and product selectivity were calculated according to equations 1 and 2, respectively.

Glycerol conversion $=\frac{\text { Moles of reacted glycerol }}{\text { Moles of initial glycerol }} \times 100$

Product selectivity $=\frac{\text { Moles of obtained product }}{\text { Total moles of product }} \times 100$

\section{Results and Discussion}

The chemical and textural analyses of the catalysts and supports are shown in Table 1. The amount of metal obtained by chemical analysis coincides, satisfactorily, with the theoretical values added upon impregnation. The BET surface area decreases upon impregnation of the metals, with this behavior being more pronounced in the niobium phosphate catalysts. All the metal-supported niobium oxide 
catalysts presented a similar BET surface area, whereas metal-supported niobium phosphate catalysts the BET surface values were ranged between 14 to $63 \mathrm{~m}^{2} \mathrm{~g}^{-1}$.

The acid sites of the samples were characterized by temperature-programmed desorption (TPD) using $n$-butylamine as a basic probe molecule. The TPD results of the catalysts and supports are shown in Table 2. Although this method does not give the exact acid strength of the materials, it allows a ready comparison of the acidity of different catalysts. The sites were classified of medium acid strength for desorption of the base within 120 to $350^{\circ} \mathrm{C}$, whereas strong acid sites were classified for desorption of the base in the range of 350 to $550{ }^{\circ} \mathrm{C}$. The total acidity was taken from the whole range of desorption (120 to $550^{\circ} \mathrm{C}$ ). The niobium phosphate support shows a total acidity higher than the niobium oxide support. It also exhibits a significantly higher concentration of stronger acid sites. However, its acid strength is lower than niobium oxide support.

Upon metal impregnation, the total acidity of the catalysts decreased relative to the free supports. This may be partly explained by the textural characterization that results in the reduction of the BET surface area and volume pore size, indicating significant pore blockage by the metals, and, by consequence, lower acidity.

The catalysts impregnated on niobium oxide showed a decrease in the ratio of strong to medium acid sites upon metal impregnation. This behavior was particularly evident on $\mathrm{Mo} / \mathrm{V} / \mathrm{Nb}_{2} \mathrm{O}_{5}$, which showed the best result for the acrylic acid formation. For the catalysts supported over niobium phosphate, the ratio of strong to medium acidity was not significantly affected, except for the $\mathrm{Mo} / \mathrm{V} / \mathrm{NbOPO}_{4}$ that presented an important and remarkable increase with metal impregnation, probably the reason for the low acrylic acid formation.

Figures 1 and 2 show the XRD patterns of the catalysts and the calcined $\mathrm{Nb}_{2} \mathrm{O}_{5}$ and $\mathrm{NbOPO}_{4}$ supports. Niobium oxide is amorphous before calcination but forms a crystalline structure after the thermal treatment process. The XRD pattern is consistent with the formation of the orthorhombic crystalline structure, which is usually formed when calcination is carried out above $500^{\circ} \mathrm{C} .{ }^{22}$ On the other hand, niobium phosphate did not show any appreciable change in crystallinity upon calcination.

Table 1. Chemical and textural characterization of the catalysts

\begin{tabular}{|c|c|c|c|c|c|c|}
\hline \multirow{2}{*}{ Catalyst } & \multicolumn{4}{|c|}{ XRF chemical composition / \% } & \multirow{2}{*}{$\begin{array}{c}\text { BET area / } \\
\left(\mathrm{m}^{2} \mathrm{~g}^{-1}\right)\end{array}$} & \multirow{2}{*}{$\begin{array}{l}\text { Pore volume / } \\
\qquad\left(\mathrm{cm}^{3} \mathrm{~g}^{-1}\right)\end{array}$} \\
\hline & $\mathrm{P}$ & $\mathrm{V}$ & Mo & $\mathrm{Co}$ & & \\
\hline $\mathrm{Nb}_{2} \mathrm{O}_{5}$ & - & - & - & - & 40 & 0.117 \\
\hline $\mathrm{Co} / \mathrm{V} / \mathrm{Nb}_{2} \mathrm{O}_{5}$ & - & 0.5 & - & 0.6 & 18 & 0.076 \\
\hline $\mathrm{Mo} / \mathrm{Co} / \mathrm{Nb}_{2} \mathrm{O}_{5}$ & - & - & 0.4 & 0.7 & 24 & 0.087 \\
\hline $\mathrm{Mo} / \mathrm{V} / \mathrm{Nb}_{2} \mathrm{O}_{5}$ & - & 0.6 & 0.3 & - & 25 & 0.083 \\
\hline $\mathrm{NbOPO}_{4}$ & 6.3 & - & - & - & 162 & 0.182 \\
\hline $\mathrm{Co} / \mathrm{V} / \mathrm{NbOPO}_{4}$ & 2.6 & 0.9 & - & 0.8 & 63 & 0.221 \\
\hline $\mathrm{Mo} / \mathrm{Co} / \mathrm{NbOPO}_{4}$ & 3.7 & - & 0.4 & 0.4 & 29 & 0.183 \\
\hline $\mathrm{Mo} / \mathrm{V} / \mathrm{NbOPO}_{4}$ & 2.6 & 0.9 & 0.4 & - & 14 & 0.063 \\
\hline
\end{tabular}

XRF: X-ray fluorescence; BET: Brunauer-Emmett-Teller.

Table 2. Acidity by $n$-butylamine termodesorption

\begin{tabular}{|c|c|c|c|c|}
\hline \multirow{2}{*}{ Catalyst } & \multicolumn{4}{|c|}{ Acidity / $\left(\mu \mathrm{mol} \mathrm{g}{ }^{-1} \mathrm{NH}_{3}\right)$} \\
\hline & Medium $^{\mathrm{a}}$ & Strong $^{\mathrm{b}}$ & $\mathrm{S} / \mathrm{M}$ ratio $^{\mathrm{c}}$ & Total \\
\hline $\mathrm{Nb}_{2} \mathrm{O}_{5}$ & 98 & 74 & 0.76 & 172 \\
\hline $\mathrm{Co} / \mathrm{V} / \mathrm{Nb}_{2} \mathrm{O}_{5}$ & 114 & 56 & 0.49 & 170 \\
\hline $\mathrm{Mo} / \mathrm{Co} / \mathrm{Nb}_{2} \mathrm{O}_{5}$ & 51 & 24 & 0.47 & 75 \\
\hline $\mathrm{Mo} / \mathrm{V} / \mathrm{Nb}_{2} \mathrm{O}_{5}$ & 60 & 9 & 0.15 & 69 \\
\hline $\mathrm{NbOPO}_{4}$ & 456 & 149 & 0.33 & 605 \\
\hline $\mathrm{Co} / \mathrm{V} / \mathrm{NbOPO}_{4}$ & 169 & 53 & 0.31 & 222 \\
\hline $\mathrm{Mo} / \mathrm{Co} / \mathrm{NbOPO}_{4}$ & 280 & 88 & 0.31 & 368 \\
\hline $\mathrm{Mo} / \mathrm{V} / \mathrm{NbOPO}_{4}$ & 91 & 48 & 0.53 & 139 \\
\hline
\end{tabular}

${ }^{a}$ Associated with desorption of the base between 120 and $350{ }^{\circ} \mathrm{C}$; bassociated with desorption of the base between 350 and $550{ }^{\circ} \mathrm{C}$; ${ }^{\mathrm{c}}$ ratio of strong to medium acidity. 


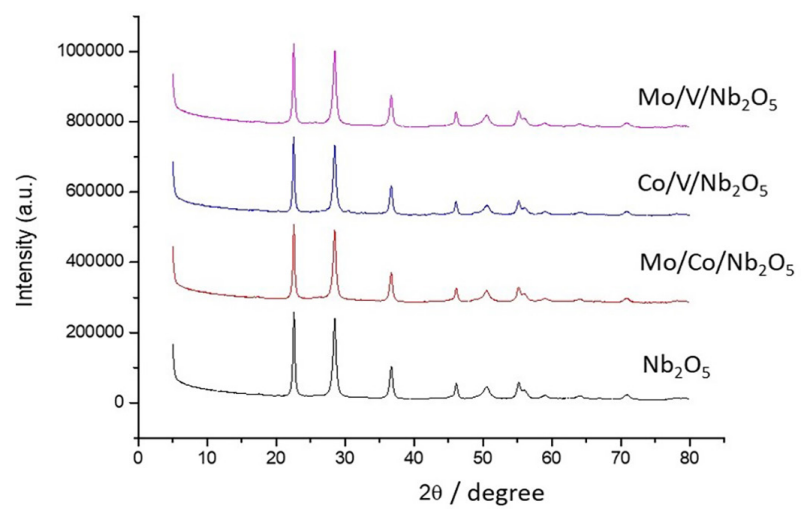

Figure 1. XRD patterns of metallic catalysts supported on $\mathrm{Nb}_{2} \mathrm{O}_{5}$.

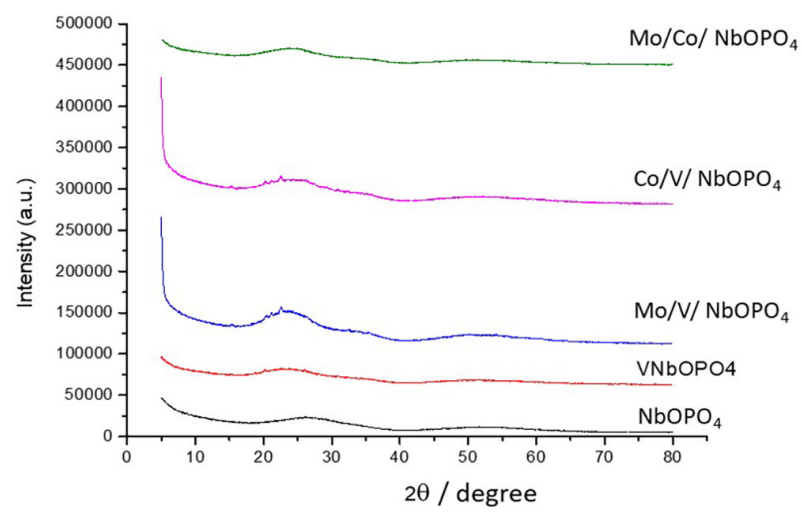

Figure 2. XRD patterns of metallic catalysts supported in $\mathrm{NbOPO}_{4}$.

The results indicate that the crystalline phases of the niobium oxide-based catalysts are mostly identical to the free support, and no clear peak related to crystalline phases of the metal oxides could be observed. The absence of peaks related to the crystalline phase of the metal oxides suggests that the metal phases could be highly dispersed on the surface forming tiny particles, invisible to XRD diffraction. However, we cannot completely rule out the partial incorporation into the structure of the niobium support, forming solid solutions. Indeed, some literature studies on $\mathrm{V}_{2} \mathrm{O}_{5}$ and $\mathrm{MoO}_{3}$ supported on $\mathrm{Nb}_{2} \mathrm{O}_{5}$ pointed out that the crystalline phase of vanadium oxide is only detected when the concentration of the metal is above $15 \mathrm{wt} . \%$, whereas the crystalline phase of $\mathrm{MoO}_{3}$ can be observed for concentrations above $5 \mathrm{wt} . \% .^{23}$

It is known that niobium phosphate is an amorphous material and becomes crystalline only after heating above $800{ }^{\circ} \mathrm{C} .{ }^{24}$ This characteristic is maintained after the metal impregnation. In this work, the metal-impregnated niobium phosphate catalysts were calcined at $550{ }^{\circ} \mathrm{C}$ and no crystalline phases, either of the metal oxides or the support, could be identified. It has been reported that the crystalline $\mathrm{V}_{2} \mathrm{O}_{5}$ phase supported on niobium phosphate is only visible when the vanadium content is $25 \mathrm{wt} . \%$. No diffraction peaks were observed for values of vanadium between 5 and $15 \mathrm{wt} . \%$, due to the high dispersion of the metal over the surface of the support. ${ }^{25}$

The catalytic tests were performed within $450 \mathrm{~min}$ on stream. All catalysts were active for glycerol oxidehydration. It was reported that catalysts for the dehydration of glycerol to acrolein and oxidehydration of glycerol produce coke and deactivate in a matter of hours. ${ }^{26}$ The transient activation of the catalysts has been recognized in many catalysts, showing that selectivity to acrolein is increasing over time. However, no significant deactivation was observed within this period.

Table 3 shows the results of glycerol conversion and product selectivity to organic compounds over niobium oxide and niobium phosphate supports under $\mathrm{N}_{2}$ flow at $300{ }^{\circ} \mathrm{C}$. In both catalysts, acrolein was the main product, indicating that these acidic supports are good catalysts for glycerol dehydration, showing 100\% conversion under the reaction conditions used in the experiments. Other observed organic products were acetaldehyde, formaldehyde, and acetol. This last product was only formed over niobium phosphate. Acetaldehyde is probably formed by the cracking of the 3-hydroxypropanal intermediate, whereas acetic acid can be produced by oxidation of the formed acetaldehyde.

Table 3. Glycerol dehydration over niobium-based supports

\begin{tabular}{lcc}
\hline Support & $\mathrm{Nb}_{2} \mathrm{O}_{5}$ & $\mathrm{NbOPO}_{4}$ \\
\hline Conversion / \% & 100 & 100 \\
\hline Selectivity / \% & & \\
\hline Acrolein & 74 & 80 \\
Acetaldehyde & 20 & 5 \\
Formaldehyde & 6 & 3 \\
Hydroxyacetone & - & 12 \\
\hline
\end{tabular}

Reaction conditions: $100 \mathrm{mg}$ of catalyst, $50 \mathrm{vol} \%$ glycerol aqueous solution, $0.5 \mathrm{~mL} \mathrm{~h}^{-1} \mathrm{~N}_{2}$ flow rate, at $300{ }^{\circ} \mathrm{C}, 450 \mathrm{~min}$.

Figures 3 and 4 show the conversion and selectivity to organic compounds of the glycerol oxidehydration over metal-impregnated $\mathrm{Nb}_{2} \mathrm{O}_{5}$ and $\mathrm{NbOPO}_{4}$ catalysts, respectively. The conversion was $100 \%$ for all catalysts, indicating that the acidity of the materials was enough to catalyze the dehydration of the glycerol molecule. This fact reinforces the hypothesis that, under these conditions, the reaction does not require catalysts of high acidity, as those observed for metal-free supports. Indeed, it seems that sites of medium acid strength play an important role in the catalytic glycerol oxidehydration to acrylic acid. For instance, the $\mathrm{Mo} / \mathrm{V} / \mathrm{Nb}_{2} \mathrm{O}_{5}$ catalyst presented the lowest amount of strong acid sites $\left(9 \mu \mathrm{mol} \mathrm{g}{ }^{-1} \mathrm{NH}_{3}\right)$ and total acidity $\left(69 \mu \mathrm{mol} \mathrm{g}{ }^{-1} \mathrm{NH}_{3}\right)$, but the same conversion as the 
other catalysts. In addition, the selectivity to acrylic acid was one of the highest, with a value of $10 \%$, over the same catalyst. The tuning of the acid strength is important to prevent undesired secondary reactions. Zeolites and other strong acids, for example, catalyze many side reactions, decreasing the selectivity to acrolein. ${ }^{27}$

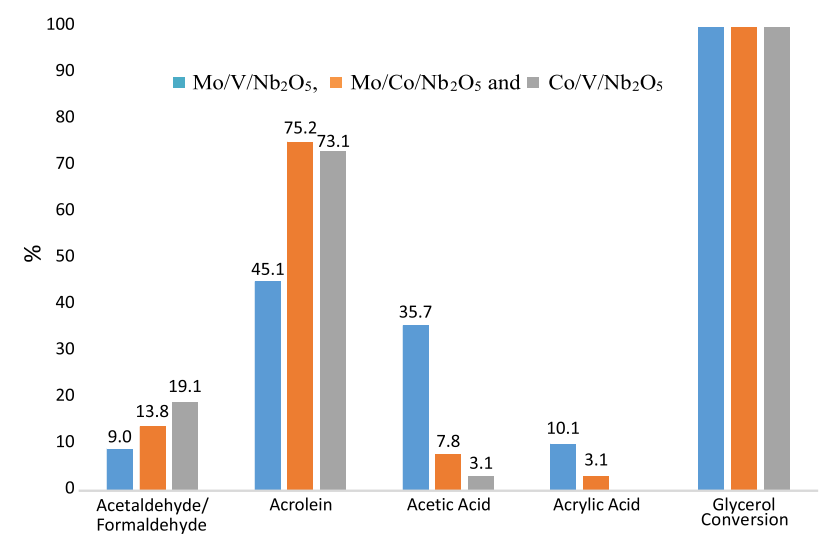

Figure 3. Conversion and selectivity to organic products of the glycerol oxidative dehydration over metallic catalysts supported on $\mathrm{Nb}_{2} \mathrm{O}_{5}$. Reaction conditions: $100 \mathrm{mg}$ of catalyst, $50 \mathrm{vol} \%$ glycerol aqueous solution, $0.5 \mathrm{~mL} \mathrm{~h}^{-1}$ air flow rate, at $300{ }^{\circ} \mathrm{C}, 450 \mathrm{~min}$.

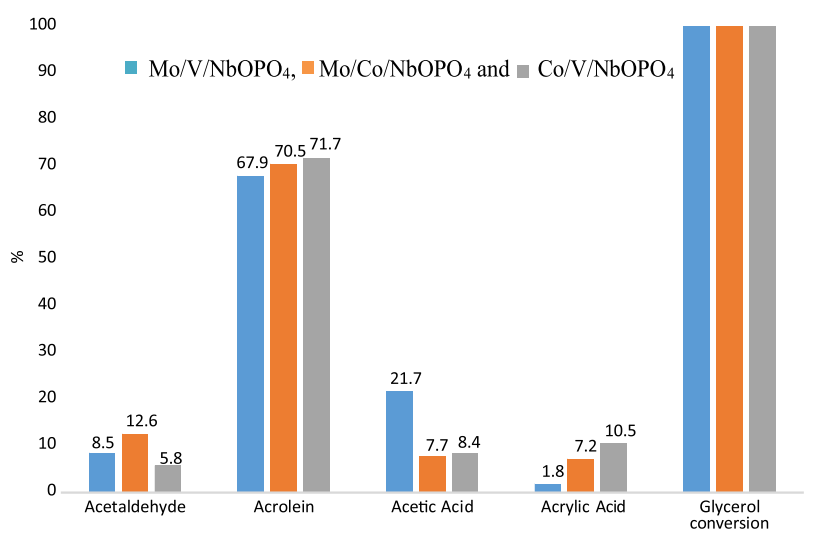

Figure 4. Conversion and selectivity to organic products of the glycerol oxidative dehydration over metallic catalysts supported on $\mathrm{NbOPO}_{4}$. Reaction conditions: $100 \mathrm{mg}$ of catalyst, $50 \mathrm{vol} \%$ glycerol aqueous solution, $0.5 \mathrm{~mL} \mathrm{~h}^{-1}$ air flow rate, at $300{ }^{\circ} \mathrm{C}, 450 \mathrm{~min}$.

All catalysts showed mostly the same products, with acrolein being the major one on all of them. These results suggest that the acidity of the catalytic system is well-tuned for glycerol dehydration to acrolein. The acrylic acid, which is another organic compound of great industrial interest, presented a selectivity of $10 \%$ in most of the tested catalysts, implying that the catalyst studied were active for the oxidation of acrolein to acrylic acid. Therefore, this study indicates a great potential of application for this metal-impregnated niobium catalyst system.

The only catalyst that did not produce acrylic acid under the conditions chosen in this work was the $\mathrm{Co} / \mathrm{V} / \mathrm{Nb}_{2} \mathrm{O}_{5}$
(Figure 3). This catalyst presented total acidity similar to the support alone and half of its BET area value. Nevertheless, the same metallic system supported over niobium phosphate gave the highest selectivity to acrylic acid (10.5\%) among the catalysts tested. Considering the same support, the acrylic acid selectivity seems to be related to the BET surface area, pore volume size, and acidity strength, but not with the composition of the metallic phase.

Although $\mathrm{V}$ and Mo oxides are traditional components of oxidation catalysts, cobalt has been reported to be a promoter in the oxidation of propene to acrolein over metal oxide catalysts, leading to higher conversion and acrolein yield. ${ }^{28}$ In addition, it has also been reported ${ }^{29}$ that $\mathrm{Co}$ and Mo oxides can be used together as an efficient catalytic system for the vapor phase oxidation of acrolein to acrylic acid.

These data support the hypothesis that the main reason for the poor selectivity to acrylic acid is related to the optimization of the metallic function and accordingly, the nature of surface sites, which also depend on the properties of the support. Therefore, by modifying the properties of the support, the reactivity of the metallic phase may also change. The main challenge is the optimization of the metal oxide loading without promoting extensive oxidation of the glycerol molecule to other products, as well as complete oxidation to form $\mathrm{CO}_{2}$ and $\mathrm{CO}$.

It is interesting to note that hydroxyacetone was not observed over the impregnated catalysts, but it was formed over pure $\mathrm{NbOPO}_{4}$. This might imply that the reduction of the total acidity, especially the strong acid sites, affects the selectivity of glycerol dehydration. Hydroxyacetone is the product of dehydration of the primary hydroxyl of glycerol (Scheme 2). Previous literature results indicate that Lewis acidity is of prime importance for the formation of hydroxyacetone. ${ }^{30,31}$ Nevertheless, in situ infrared measurements ${ }^{32}$ revealed that, although the Lewis acid sites of $\mathrm{Nb}_{2} \mathrm{O}_{5}$ are involved in the dehydration of the primary hydroxyl of the glycerol molecule, the formed enol intermediate, 2-propene-1,2-diol, is stabilized on the catalyst surface and do not straightforwardly tautomerize to hydroxyacetone. On the other hand, dehydration of the secondary hydroxyl forms the enol intermediate 1,3-propenediol, which is not spectroscopically observed on the $\mathrm{Nb}_{2} \mathrm{O}_{5}$ surface and may desorb as 3-hydroxypropanal, which in turn may be further dehydrated to acrolein. These considerations may explain the results.

The $\mathrm{NbOPO}_{4}$ support has almost twice the number of strong acid sites than $\mathrm{Nb}_{2} \mathrm{O}_{5}\left(149 \mu \mathrm{mol} \mathrm{g}{ }^{-1}\right.$ for $\mathrm{NbOPO}_{4}$ and $74 \mu \mathrm{mol} \mathrm{g}^{-1}$ for $\mathrm{Nb}_{2} \mathrm{O}_{5}$ ), and the total acidity is more than three times higher $\left(605 \mu \mathrm{mol} \mathrm{g}{ }^{-1}\right.$ for $\mathrm{NbOPO}_{4}$ and $172 \mu \mathrm{mol} \mathrm{g} \mathrm{g}^{-1}$ for $\mathrm{Nb}_{2} \mathrm{O}_{5}$ ). It has also been reported that 


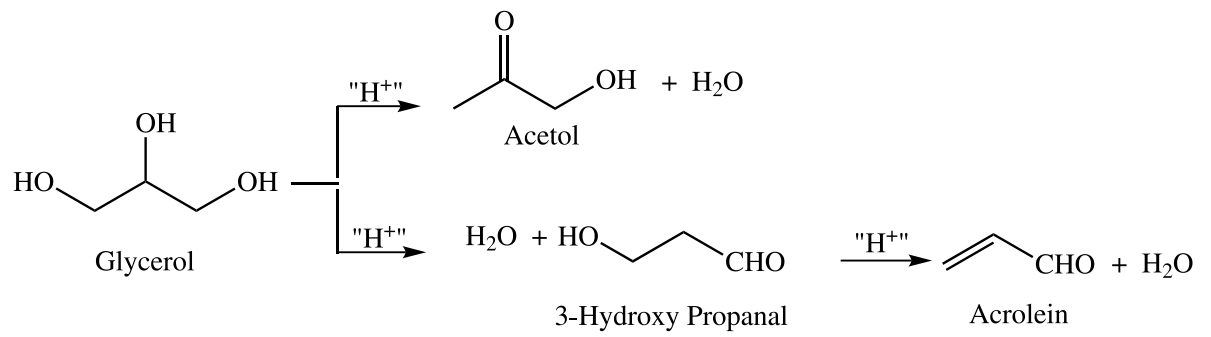

Scheme 2. Acid-catalyzed dehydration of glycerol; formation of acetol upon dehydration of the primary hydroxyl or formation of 3-hydroxy propanal upon dehydration of the secondary hydroxyl.

niobium phosphate possesses more Brønsted than Lewis acid sites, whereas on niobium oxide Lewis acidity prevails when the solid is calcined at $300{ }^{\circ} \mathrm{C} .{ }^{33}$ But this profile changes with increasing pretreatment temperature, due to the transformation of the protonic acid sites in Lewis acid sites by water elimination and loss of surface area. ${ }^{34}$

In a previous study, ${ }^{12}$ using vanadium-impregnated zeolite Beta, the selectivity to acrylic acid was around $25 \%$ with a glycerol conversion of $70 \%$ at $275^{\circ} \mathrm{C}$. Other studies $^{8-10}$ on the use of bifunctional catalysts report selectivity to acrylic acid in the range of 5 to $30 \%$, at different reaction conditions and conversion levels. On the other hand, massic mixed oxides of tungsten, vanadium, and niobium gave 50\% selectivity to acrylic acid at 100\% glycerol conversion. ${ }^{35}$ The selectivity to acrolein is, however, rather low, in the range of $3 \%$, with the formation of $\mathrm{CO}$ and $\mathrm{CO}_{2}$, as well as other heavier products.

In this work, although $\mathrm{CO}$ and $\mathrm{CO}_{2}$ formed during the tests have not been measured online, it was possible to quantify the $\mathrm{CO}$ and $\mathrm{CO}_{2}$ content, in control experiments where a sample of the reactor effluent was collected and analyzed in a thermal conductivity detector (TCD) gas chromatograph. The results indicated that about $18 \%$ of the glycerol is transformed in $\mathrm{CO}_{2}$ over $\mathrm{Mo} / \mathrm{V} / \mathrm{Nb}_{2} \mathrm{O}_{5}$ catalyst in the same reaction conditions used in this work. Therefore, considering the mass balance and taking into account the formed inorganic gaseous products (CO and $\mathrm{CO}_{2}$ ), the corrected selectivity to acrolein plus acrylic acid (A + AA) could be obtained for this catalyst. Table 4 shows a comparison of the reported selectivity to acrolein and acrylic acid with other studies, where the amount of $\mathrm{CO}$ and $\mathrm{CO}_{2}$ formed was reported.

It is possible to observe that $\mathrm{Mo} / \mathrm{V} / \mathrm{Nb}_{2} \mathrm{O}_{5}$ catalyst shows $60 \%$ of selectivity to acrolein plus acrylic acid. Massic mixed oxides, although producing higher amounts of acrylic acid, gave lower selectivity to acrolein plus acrylic acid, consistent with the high activity of these catalysts to the complete oxidation of the organic compounds to $\mathrm{CO}$ and $\mathrm{CO}_{2} \cdot{ }^{35,36}$ Vanadium phosphate showed the highest selectivity to acrolein plus acrylic acid, around $69 \%$, at $300{ }^{\circ} \mathrm{C}$, with only $1 \%$ of $\mathrm{CO}_{2} \cdot{ }^{37}$ Nevertheless, this value
Table 4. Conversion and selectivity to acrolein plus acrylic acid of the glycerol oxidehydration over different catalytic systems and conditions

\begin{tabular}{|c|c|c|c|c|}
\hline \multirow{2}{*}{ Catalyst } & \multirow{2}{*}{$\begin{array}{c}\text { Conversion / } \\
\%\end{array}$} & \multicolumn{2}{|c|}{ Selectivity / \% } & \multirow{2}{*}{ Reference } \\
\hline & & $\mathrm{A}+\mathrm{AA}$ & $\mathrm{COx}$ & \\
\hline V-W-Nb oxides & 100 & 53 & 30 & 13 \\
\hline $\mathrm{VOHPO}_{4}{ }^{\mathrm{a}}$ & 100 & 69 & 1 & 36 \\
\hline $\mathrm{VOHPO}_{4}{ }^{\mathrm{b}}$ & 100 & 44 & 22 & 36 \\
\hline Mo-V-Te-Nb oxides & 100 & 30 & 45 & 37 \\
\hline $\mathrm{V}_{2} \mathrm{O}_{5} / \mathrm{ZSM}-5$ & 100 & 32 & 60 & 38 \\
\hline $\mathrm{Mo} / \mathrm{V} / \mathrm{Nb}_{2} \mathrm{O}_{5}$ & 100 & 60 & 18 & this work \\
\hline
\end{tabular}

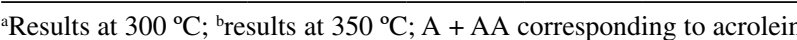
plus acrylic acid.

mostly accounts for acrolein (66\%), with acrylic acid being formed in only $3 \%$. When the temperature was increased to $350{ }^{\circ} \mathrm{C}$, the selectivity to acrylic acid was $8 \%$, but the selectivity to acrolein decreased to $36 \%$, whilst the amount of $\mathrm{CO}$ and $\mathrm{CO}_{2}$ accounted for $22 \%$. These results indicate the potential of the metal oxide systems supported over $\mathrm{Nb}_{2} \mathrm{O}_{5}$ as catalysts for the oxidehydration of glycerol to acrolein and acrylic acid. The main advantage is the low formation of byproducts, especially heavier ones, with high selectivity to the desired products. Therefore, the acidic properties of niobium-based catalysts appear to be well suited for the dehydration of glycerol to acrolein. By evaluating the function of metal oxides, it was possible to observe their ability to oxidize acrolein to acrylic acid by up to $10 \%$. This result indicates a great potential of these bifunctional catalysts to produce acrylic acid in a single step, from glycerol oxidehydration.

\section{Conclusions}

The oxidative dehydration of glycerol to organic compounds such as acrolein and acrylic acid over metalimpregnated niobium oxide and niobium phosphate catalysts was studied. Although the acidity of the supports was significantly reduced upon metal impregnation, all tested materials presented $100 \%$ conversion. These results indicate that the glycerol dehydration to acrolein does not 
require strong acid sites at the conditions used in this study and that the niobium-based supports are well adjusted, in terms of acidity, to catalyze this reaction.

The main organic product in all catalysts was acrolein, with selectivity ranging from 50 to $70 \%$, approximately. Acrylic acid was produced in up $10 \%$ selectivity, with the remaining products being acetaldehyde/formaldehyde and acetic acid. All catalysts did not show significant deactivation during $450 \mathrm{~min}$ on stream, indicating that either the formed coke is burned at the reaction conditions or the acid function was well adjusted to prevent coke deposition.

Although the niobium supports appear to have the suitable acidity (number and strength) to dehydrate glycerol to acrolein, the metal oxide function still deserves attention to improve the selectivity to acrylic acid without increasing the amount of $\mathrm{CO}$ and $\mathrm{CO}_{2}$. Over the $\mathrm{Mo} / \mathrm{V} / \mathrm{Nb}_{2} \mathrm{O}_{5}$ catalyst, the selectivity to acrolein plus acrylic acid, both products of great industrial relevance, are among the highest reported in the literature, indicating that the formation of undesired byproducts is not much significant over the catalytic system studied, which points out for the potential sustainability of the process.

\section{Acknowledgments}

Authors thank FAPERJ, CNPq, PRH-ANP, and FINEP for financial support.

\section{References}

1. Pinto, A. C.; Guarieiro, L. L. N.; Rezende, M. J. C.; Ribeiro, N. M.; Torres, E. A.; Lopes, W. A.; Pereira, P. A. P.; de Andrade, J. B.; J. Braz. Chem. Soc. 2005, 16, 1313.

2. Mota, C. J. A.; Pinto, B. P.; de Lima, A. L.; Glycerol: A Versatile Renewable Feedstock for the Chemical Industry; Springer: Cham, Switzerland, 2017.

3. Behr, A.; Eilting, J.; Irawadi, K.; Leschinski, J.; Lindner, F.; Green Chem. 2008, 10, 13.

4. Mota, C. J. A.; Silva, C. X. A. D.; Gonçalves, V. L. C.; Quim. Nova 2009, 32, 639 .

5. Andrushkevich, T. V.; Catal. Rev. 1993, 35, 213.

6. Kampe, P.; Giebeler, L.; Samuelis, D.; Kunert, J.; Drochner, A.; Haaß, F.; Adams, A. H.; Ott, J.; Endres, S.; Schimanke, G.; Buhrmester, T.; Martin, M.; Fuess, H.; Vogel, H.; Phys. Chem. Chem. Phys. 2007, 9, 3577.

7. Mohamad, M. H.; Awang, R.; Yunus, W. M. Z. W.; Am. J. Appl. Sci. 2011, 8, 1135.

8. Wang, F.; Dubois, J. L.; Ueda, W.; Appl. Catal., A 2010, 376, 25.

9. Wang, F.; Xu, J.; Dubois, J. L.; Ueda, W.; ChemSusChem 2010 , 3,1383 .
10. Soriano, M. D.; Concepción, P.; Nieto, J. M. L.; Cavani, F.; Guidetti, S.; Trevisanut, C.; Green Chem. 2011, 13, 2954.

11. Chieregato, A.; Basile, F.; Concepción, P.; Guidetti, S.; Liosi, G.; Soriano, M. D.; Trevisanut, C.; Cavani, F.; Nieto, J. M. L.; Catal. Today 2012, 197, 58.

12. Pestana, C. F. M.; Guerra, A. C. O.; Ferreira, G. B.; Turci, C. C.; Mota, C. J. A.; J. Braz. Chem. Soc. 2013, 24, 100.

13. Possato, L. G.; Cassinelli, W. H.; Garetto, T.; Pulcinelli, S. H.; Santilli, C. V.; Martins, L.; Appl. Catal., A 2015, 492, 243.

14. Paula, A. S.; Possato, L. G.; Ratero, D. R.; Contro, J.; KeinanAdamsky, K.; Soares, R. R.; Goobes, G.; Martins, L.; Nery, J. G.; Microporous Mesoporous Mater. 2016, 232, 151.

15. Omata, K.; Matsumoto, K.; Murayama, T.; Ueda, W.; Catal. Today 2016, 259, 205.

16. Li, X.; Zhang, Y.; ACS Catal. 2016, 6, 2785.

17. Rasteiro, L. F.; Vieira, L. H.; Possato, L. G.; Pulcinelli, S. H.; Santilli, C. V.; Martins, L.; Catal. Today 2017, 296, 10.

18. Rasteiro, L. F.; Vieira, L. H.; Santilli, C. V.; Martins, L.; RSC Adv. 2018, 8, 11975.

19. Vieira, L. H.; Lopez-Castillo, A.; Jones, C. W.; Martins, L.; Appl. Catal., A 2020, 602, 117687.

20. Gonçalves, V. L. C.; Rodrigues, R. C.; Lorençato, R.; Mota, C. J. A.; J. Catal. 2007, 248, 158.

21. Gonçalves, V. L. C.; Pinto, B. P.; Silva, J. C.; Mota, C. J. A.; Catal. Today 2008, 133-135, 673.

22. Eblagon, K. M.; Malaika, A.; Ptaszynska, K.; Pereira, M. F. R.; Figueiredo, J. L.; Nanomaterials 2020, 10, 1685.

23. Jehng, J. M.; Turek, A. M.; Wachs, I. E.; Appl. Catal., A 1992 , $83,179$.

24. Tang, Z. C.; Yu, D. H.; Sun, P.; Li, H.; Huang, H.; Bull. Korean Chem. Soc. 2010, 31, 3679.

25. Sun, Q.; Fang, D.; Wang, S.; Shen, J.; Auroux, A.; Appl. Catal., A 2007, 327, 218.

26. Dalil, M.; Carnevali, D.; Edake, M.; Auroux, A.; Dubois, J. L.; Patience, G. S.; J. Mol. Catal. A: Chem. 2016, 421, 146.

27. Chai, S. H.; Wang, H. P.; Liang, Y.; Xu, B. Q.; Green Chem. 2007, 9, 1130.

28. Udalova, O. V.; Shashkin, D. P.; Shibanova, M. D.; Krylov, O. V.; Kinet. Catal. 2005, 46, 569.

29. Campos, D.; Hecquet, G.; Pham, C.; US pat. 006310240B1, 2001.

30. Katryniok, B.; Paul, S.; Bellière-Baca, V.; Rey, P.; Dumeignil, F.; Green Chem. 2010, 12, 2079.

31. Belousov, A. S.; ChemistrySelect 2021, 6, 9191.

32. Foo, G. S.; Wei, D.; Sholl, D. S.; Sievers, C.; ACS Catal. 2014, 4, 3180

33. Bassan, I. A. L.; Nascimento, D. R.; San Gil, R. A. S.; da Silva, M. I. P.; Moreira, C. R.; Gonzalez, W. A.; Faro, A. C.; Onfroy, T.; Lachter, E. R.; Fuel Process. Technol. 2013, 106, 619.

34. Nowak, I.; Ziolek, M.; Chem. Rev. 1999, 99, 3603. 
35. Chieregato, A.; Soriano, M. D.; Basile, F.; Liosi, G.; Zamora, S.; Concepción, P.; Cavani, F.; López Nieto, J. M.; Appl. Catal., B 2014, 150-151, 37.

36. Doornkamp, C.; Ponec, V.; J. Mol. Catal. A: Chem. 2000, 162, 19.
37. Possato, L. G.; Diniz, R. N.; Garetto, T.; Pulcinelli, S. H.; Santilli, C. V.; Martins, L.; J. Catal. 2013, 300, 102.

38. Wang, F.; Dubois, J. L.; Ueda, W.; J. Catal. 2009, 268, 260.

Submitted: September 10, 2021

Published online: February 22, 2022 